\title{
UN ENCLAVE ARCAICO TARDÍO EN LA AGUADA COSTERA DE GUALAGUALA (DESIERTO DE ATACAMA, NORTE DE CHILE)
}

\author{
A LATE ARCHAIC ENCLAVE IN THE GUALAGUALA COASTAL SPRING \\ (ATACAMA DESERT, NORTHERN CHILE)
}

\author{
Benjamín Ballester ${ }^{1}$, Estefanía Vidal $^{2}$, Elisa Calás ${ }^{3}$, Francisco Gallardo $^{4}$, Patricio Aguilera ${ }^{5}$, \\ Constanza Pellegrino ${ }^{6}$ y Alejandro Clarot $^{7}$
}

\begin{abstract}
Presentamos el reporte inicial de recientes excavaciones de un asentamiento con arquitectura lapidaria cercano a la ciudad de Mejillones en el litoral del desierto de Atacama, datado hacia los 5000 cal. AP. Discutimos a través de su evidencia material la estrategia de importación hacia el campamento de una producción extendida geográficamente en distintos ambientes del litoral y el desierto, lo que junto a un trabajo constructivo de carácter colectivo y el uso de entierros humanos en las fundaciones de los recintos habitacionales, podría dar cuenta de una estrategia de asentamiento con campamentos residenciales estables. Propuesta que se discute junto a los datos arqueológicos de otros sitios del período Arcaico Tardío litoral (6500-4000 cal. AP).

Palabras claves: campamento residencial, complejidad social, sedentarización, cazadores-recolectores, marcadores.
\end{abstract}

We present an initial report of recent excavations of a settlement with stone architecture near the city of Mejillones, on the Atacama Desert coast, dated to $5000 \mathrm{cal}$. BP. Through analysis of its material assemblage, we discuss the strategy of import to the site of a production geographically extended over different environments on the littoral and the desert. This, together with collective labor and the presence of human interments underneath the floors of the enclosures, could account for a settlement pattern with stable residential camps. We discuss this by considering archaeological data from other sites of the Late Archaic Period on the coastal desert (6500-4000 cal. BP).

Key words: Residential camp, social complexity, sedentarization, hunter-gatherers, markers.

El antiguo modelo evolucionista y etnocentrista del neolítico que condiciona a la agricultura y domesticación de alimentos la posibilidad de alcanzar un modo de vida sedentario, ha ido perdiendo desde hace décadas popularidad dentro de las principales corrientes que explican los procesos de complejización social (Arnold 1993, 1996; Arnold et al. 2016; Bender 1978; Feinman y Neitzel 1984; Ingold et al. 1988; Sassaman 2007; Testart 1981, 1982, 1988). En este nuevo panorama ontológico, las sociedades costeras han tomado un papel protagónico como argumento etnográfico para demostrar la posibilidad real y concreta de vías alternativas en el proceso de sedentarización al alero de formas de subsistencia basadas en la caza, pesca y recolección de recursos silvestres (Ames 1981, 1995, 2001; Arnold 1992, 1996, 2001, 2004; Day et al. 2012; Firth 1946; Haas et al. 2008; Kenneth et al. 2009; Moseley 1975; Pozorsky y Pozorsky 1993; Rostworowski 2004; Schoembucher 1988; Shady et al. 2000; Suttles 1960; Yesner 1980).

Con nuevos modelos explicativos en circulación, los esfuerzos deben centrarse ahora en comprender cómo cada sociedad experimentó estos procesos de reducción y estabilización de movilidad residencial, ahondando en sus singulares mecanismos, estrategias y soluciones. En el litoral del desierto de Atacama esta temática ha sido abordada desde diversas

\footnotetext{
${ }^{1}$ UMR 7041 ArScAN, Équipe Ethnologie Préhistorique, Université Paris 1 Panthéon Sorbonne, Francia. benjaminballesterr@gmail.com

2 CONICYT/Fulbright, Doctorado Antropología, University of Chicago, USA. evidalmontero@uchicago.edu

3 Investigadora Independiente. elisa.calas@gmail.com

${ }^{4}$ CIIR, Pontificia Universidad Católica de Chile, Santiago, Chile. fgallardo.ibanez@ gmail.com

${ }^{5}$ Investigador independiente. patricio.aguilera@gmail.com

${ }^{6}$ Programa Doctorado en Antropología. UCN-UTA, Universidad Católica del Norte, San Pedro de Atacama, Chile. constanza.pellegrino@alumnos.ucn.cl

${ }^{7}$ Investigador independiente. jano.clarot@gmail.com
}

Recibido: mayo 2017. Aceptado: marzo 2018. 
materialidades y perspectivas, sin que exista aún consenso (Ballester y Gallardo 2011; Marquet et al. 2012; Muñoz 2013; Núñez y Santoro 2011; Santoro et al. 2005; Standen et al. 2004). Buscando enriquecer este debate, presentamos un caso de estudio en el litoral de Mejillones correspondiente a un campamento con arquitectura lapidaria formal fechado hacia alrededor de 5000 cal AP, llamado Aguada Gualaguala 04, de características similares a otros ya descritos del período Arcaico Tardío costero (6500-4000 cal. AP) (Ballester et al. 2014a, 2014b, 2017; Bittmann 1984; Castelleti 2007; Castro et al. 2016; Llagostra 1989, 2013; Mostny 1964; Núñez et al. 1974; Salazar et al. 2015; entre otros). Mediante el análisis de sus restos de fauna, industria lítica, rasgos arquitectónicos y evidencia bioantropológica, postulamos que estas comunidades altamente especializadas en la explotación de los recursos marinos a través de la caza, pesca y recolección, emprendieron un proceso de estabilización residencial gracias a la implementación conjunta de tres mecanismos materiales de reforzamiento, sobresignificación y territorialización de sus campamentos a través de una triple marca: habitar, construir y filiar.

\section{Bahía de Gualaguala}

A excepción del río Loa, la costa del desierto de Atacama se caracteriza por la ausencia de ríos que desaguan al mar, privándola de los ricos ambientes de desembocadura de los valles occidentales ariqueños y del centro-sur del Perú (Craig 1982; Llagostera 1989; Núñez 1968, 1999; True 1975). En el resto de la región, manantiales salobres se forman por la filtración en la cordillera de la costa de la camanchaca, permitiendo el asentamiento humano en este litoral (Craig 1982; Herrera y Custodio 2014; Lagos 1980; Llagostera 2013; Mostny 1964; Núñez y Varela 1967/1968).

Es junto a estas aguadas que los habitantes han establecido sus residencias, desde los primeros pobladores del litoral que se instalaron en la quebrada de la Chimba (Antofagasta) hace once mil años, hasta el puerto colonial y republicano de Cobija levantado en una pequeña bahía que disfrutaba de al menos tres fuentes de agua potable (Bittmann 1984; Bittmann et al. 1980; Llagostera 1979, 1989, 2013; Llagostera et al. 2000; Núñez y Varela 1967/1968).

La aguada de Gualaguala se ubica a unos $40 \mathrm{~km}$ al norte de la ciudad de Mejillones, en la sección media de una pequeña quebrada que escurre desde los pies de la cordillera de la costa hacia el mar (Figura 1). Si bien actualmente hay solo un lugar donde brota el agua desde el subsuelo, la inusual concentración de vegetales en ciertos puntos indica que en el pasado pudieron existir otros escurrimientos. La aguada favoreció las ocupaciones humanas a lo largo de toda la historia regional, desde un asentamiento Arcaico Temprano hasta una instalación para carga de minerales del siglo XIX; incluso una construcción de latones aún sirve de campamento a algueros.

En esta localidad la concentración de sitios arqueológicos es notable. En los cuatro kilómetros de costa de la bahía de Gualaguala hemos identificado hasta el momento 19 cementerios y 10 sitios residenciales de distintos momentos de la prehistoria (Figura 1), todos ellos ubicados en la planicie litoral que en su parte más ancha alcanza casi los 2,5 km antes del acantilado costero (Figura 2). De los cementerios, ocho corresponden a túmulos funerarios del período Formativo litoral (2500-1000 cal. AP) y 11 del período Intermedio Tardío y Tardío local (1000-500 cal. AP). De los sitios residenciales seis corresponden a depósitos basurales monticulares tipo conchales, mientras que otros cuatro presentan además evidencias superficiales de la arquitectura en piedra característica del Arcaico Tardío costero (6500-4000 cal. AP) (Figura 1).

Entre estos últimos destaca Aguada Gualaguala 04 (AGG-04), un conchal subcircular de $50 \mathrm{~m}$ de diámetro y $50 \mathrm{~cm}$ de alto en su sección más densa, ubicado $300 \mathrm{~m}$ quebrada abajo de la actual aguada y $800 \mathrm{~m}$ de la línea de costa $(46 \mathrm{msm})$. En el conchal se observan al menos ocho estructuras semicirculares hoy cubiertas de basuras, junto a otras cuatro superficiales construidas en momentos posteriores (Figura 2-3).

\section{La Excavación}

El sitio AGG-04 fue identificado luego de una etapa de prospección general de la bahía en la que se identificaron 26 sitios arqueológicos de gran magnitud (Figura 1). Se llevaron a cabo recolecciones superficiales en cinco de los cementerios de túmulos Formativos y sondajes para evaluar estratigrafía mediante pozos de $100 \times 50 \mathrm{~cm}$ en los cuatro conchales de mayor depósito y más cercanos a la aguada (AGG$01,02,03$ y 04$)$. Gracias a uno de esos pozos se logró despejar la pared interior del muro de piedras correspondiente a la Estructura 1 del sitio AGG-04.

Se realizó la topografía del sitio ubicando las distintas estructuras y el material arqueológico diagnóstico existente en superficie, además de un registro planimétrico de cada una de las estructuras, detallando sus medidas y distribuciones espaciales (Figura 3). Por último, se procedió a la excavación completa de la Estructura 1. Conjuntamente, se ejecutó un pozo de sondaje de 50 x $50 \mathrm{~cm}$ en el exterior del 

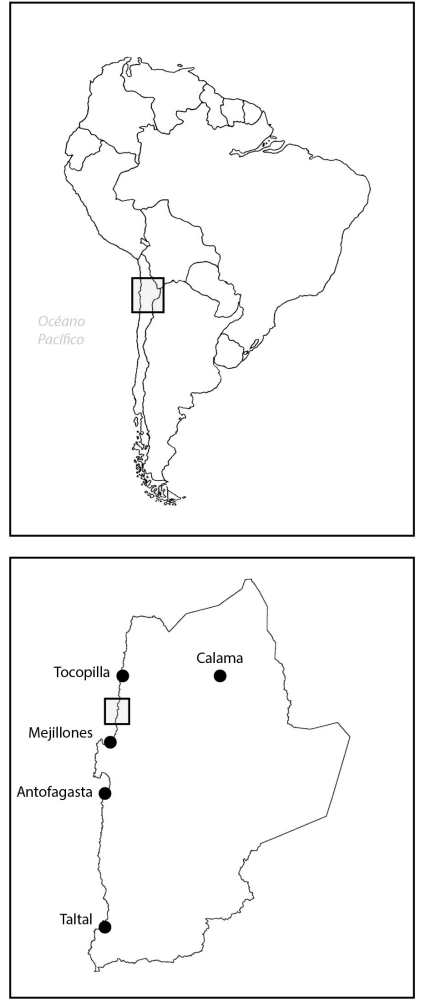

\section{Af Ag. Gualaguala 04}

- Cementerios de túmulos

- Cementerios Período Intermedio Tardío y Tardío

+ Conchales

- Aldeas Arcaico Tardío

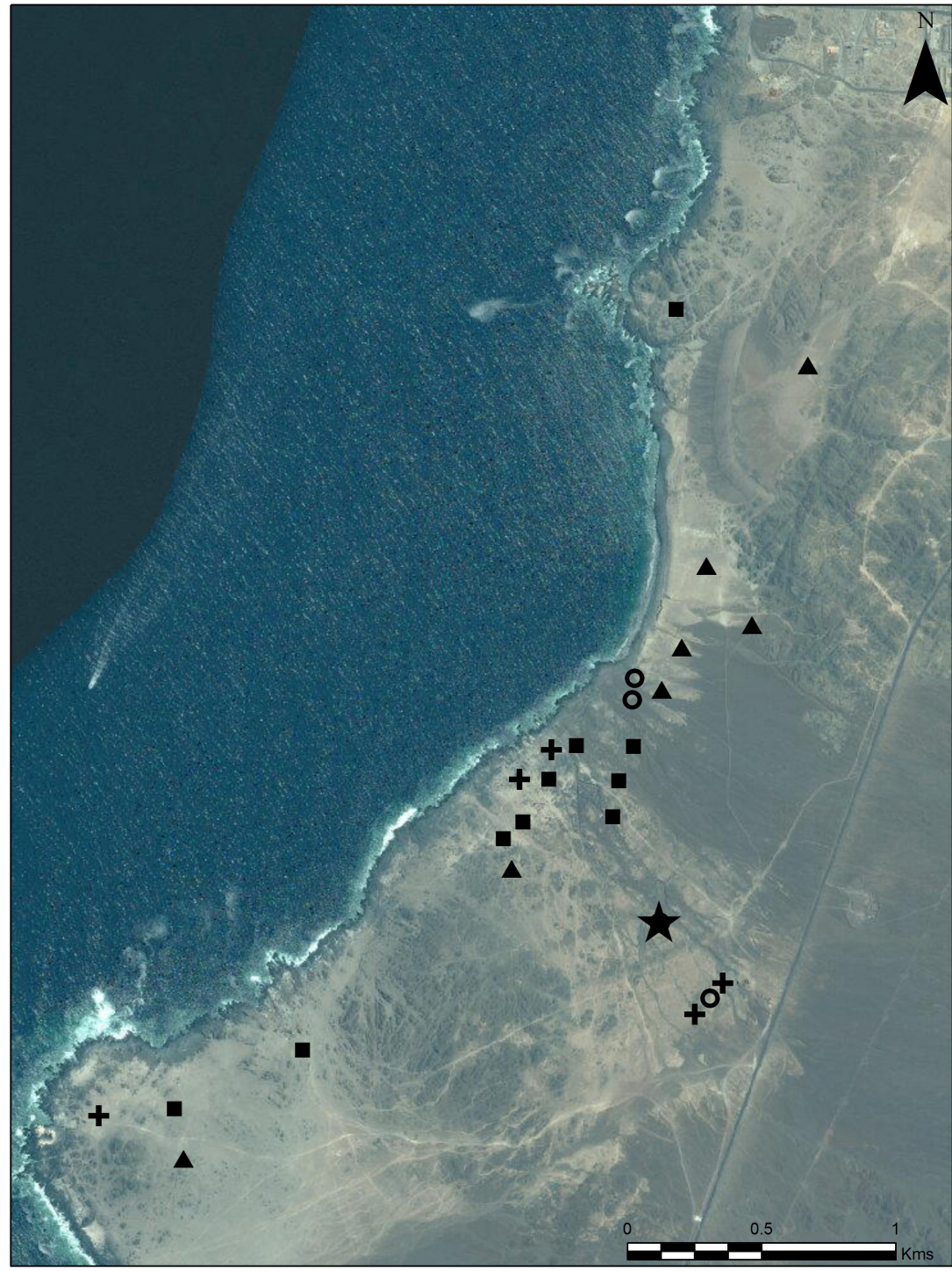

Figura 1 Mapa de la ubicación de los sitios arqueológicos de la bahía de Gualaguala (norte de Chile). Location map of the archaeological sites from the Gualaguala cove (Northern Chile). 

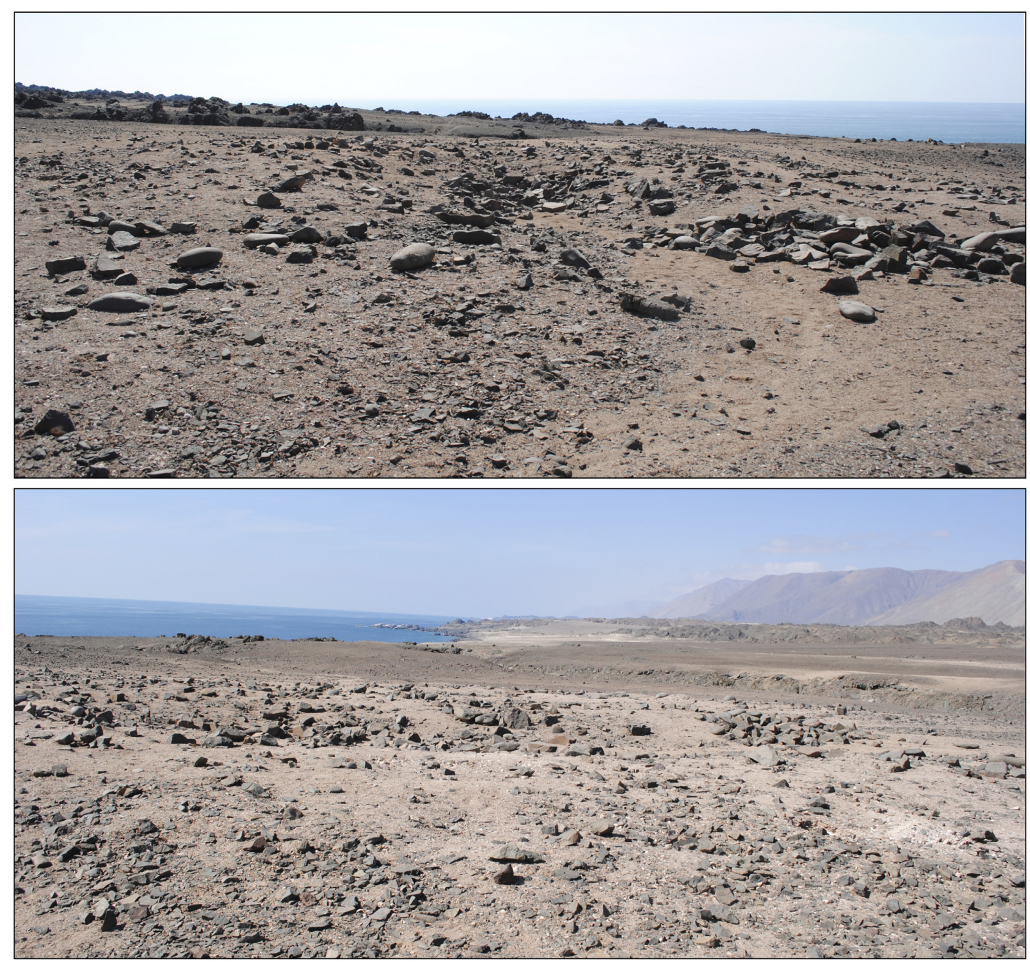

Figura 2. Bahía de Gualaguala: (arriba) vista hacia el oeste del conchal de AGG-04; (abajo) vista hacia el norte del conchal de AGG-04. Gualaguala Cove: (top) west view of AGG-04 middens; (bottom) north view of AGG-04 middens.

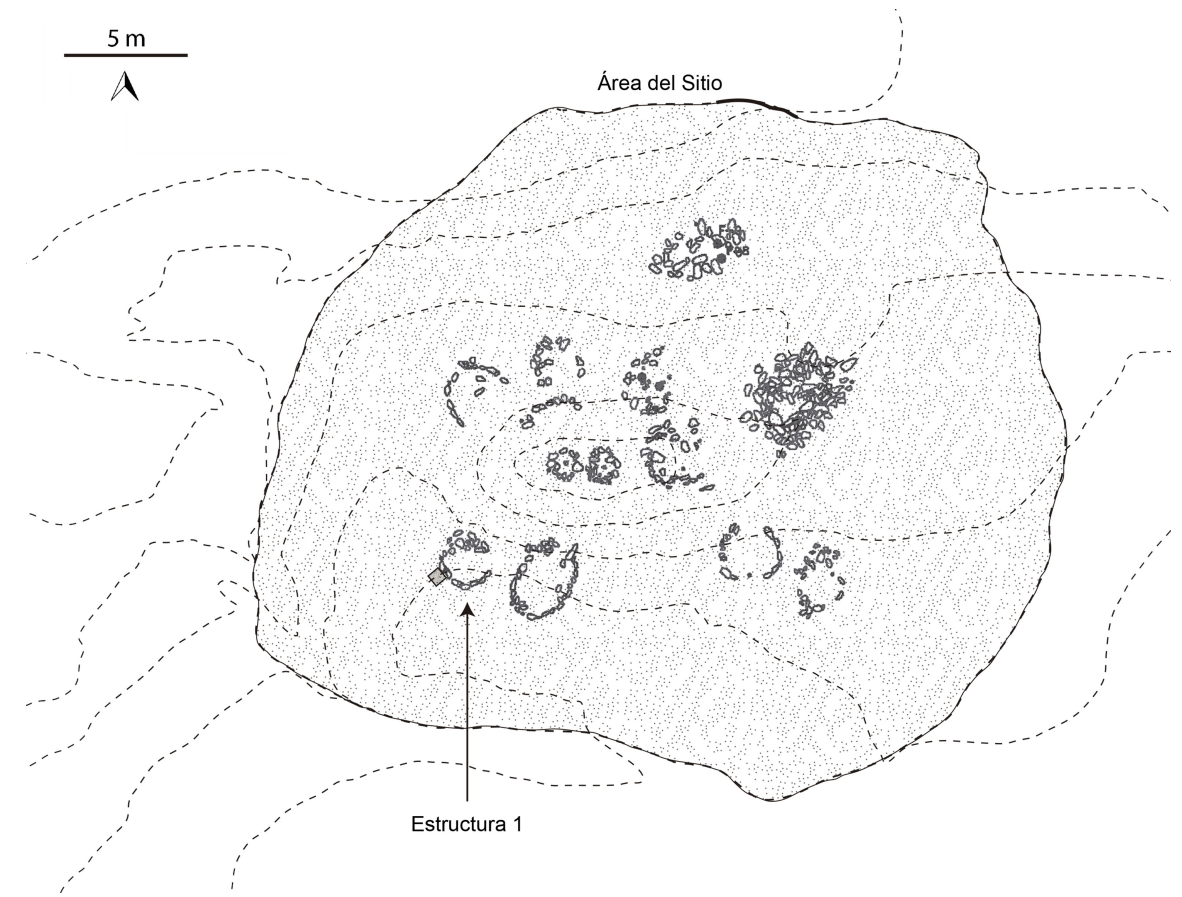

Figura 3. Plano del sitio de AGG-04 detallando la distribución de las estructuras habitacionales. AGG-04 floor plan detailing the distribution of habitation structures. 
recinto, en el extremo opuesto del vano de acceso y de mayor depósito del conchal, con la finalidad de distinguir procesos depositacionales entre interior y exterior, comparar los materiales arqueológicos e intentar definir si la estructura fue construida sobre un suelo natural, un antiguo depósito cultural o si correspondía a un recinto semisubterráneo.

La excavación se realizó siguiendo estratos depositacionales, cada uno dividido en niveles artificiales. Sin embargo, el interior del recinto arrojó una sola gran capa homogénea por sobre el piso base preparado, sin que existieran diferencias importantes de frecuencias y diversidad de materiales entre los niveles. Solo en el exterior del recinto se registraron diferentes capas estratigráficas.

\section{Resultados}

\section{Arquitectura: materiales, elementos constructivos y diseño}

El sitio corresponde a un conglomerado de ocho recintos subcirculares construidos en piedra y mortero, agrupados de manera irregular. Las estructuras están cercanas, aunque no colindantes, con accesos de orientaciones variadas, pero en su mayoría dirigidos hacia un espacio central posiblemente de carácter comunitario o de circulación (Figura 3). La Estructura 1 tiene 2,2 $\mathrm{m}$ de diámetro máximo, formando un área aproximada de $3,8 \mathrm{~m}^{2}$ de superficie, excavado en su totalidad (Figura 4).

El muro es semicircular, de aparejo rústico e hilada simple. Puede dividirse en dos secciones: en la parte inferior se encuentran los paramentos en donde fueron dispuestas lajas y piedras de manera vertical, una al lado de la otra, sobre los cuales se instalaron rocas más pequeñas y orientadas en forma horizontal formando una superposición de hileras, alcanzando un ancho promedio de $30 \mathrm{~cm}$ y una altura máxima de $70 \mathrm{~cm}$ (Figura 5A-B). Las lajas de la sección inferior fueron colocadas utilizando además un mortero hecho con cenizas de color grisáceo. Gracias a la excavación se pudo constatar que el recinto es semisubterráneo, es decir, que fue construido excavando el piso natural para emplazar las lajas verticales en el perímetro de la cavidad, esto porque el pozo de sondeo exterior mostró una diferencia del nivel estéril de $50 \mathrm{~cm}$ por sobre el suelo preparado del interior del recinto (Figura 5A). Asimismo, se observó que las piedras basales de la estructura (lajas verticales), fueron dispuestas sobre el sedimento natural del depósito estéril,

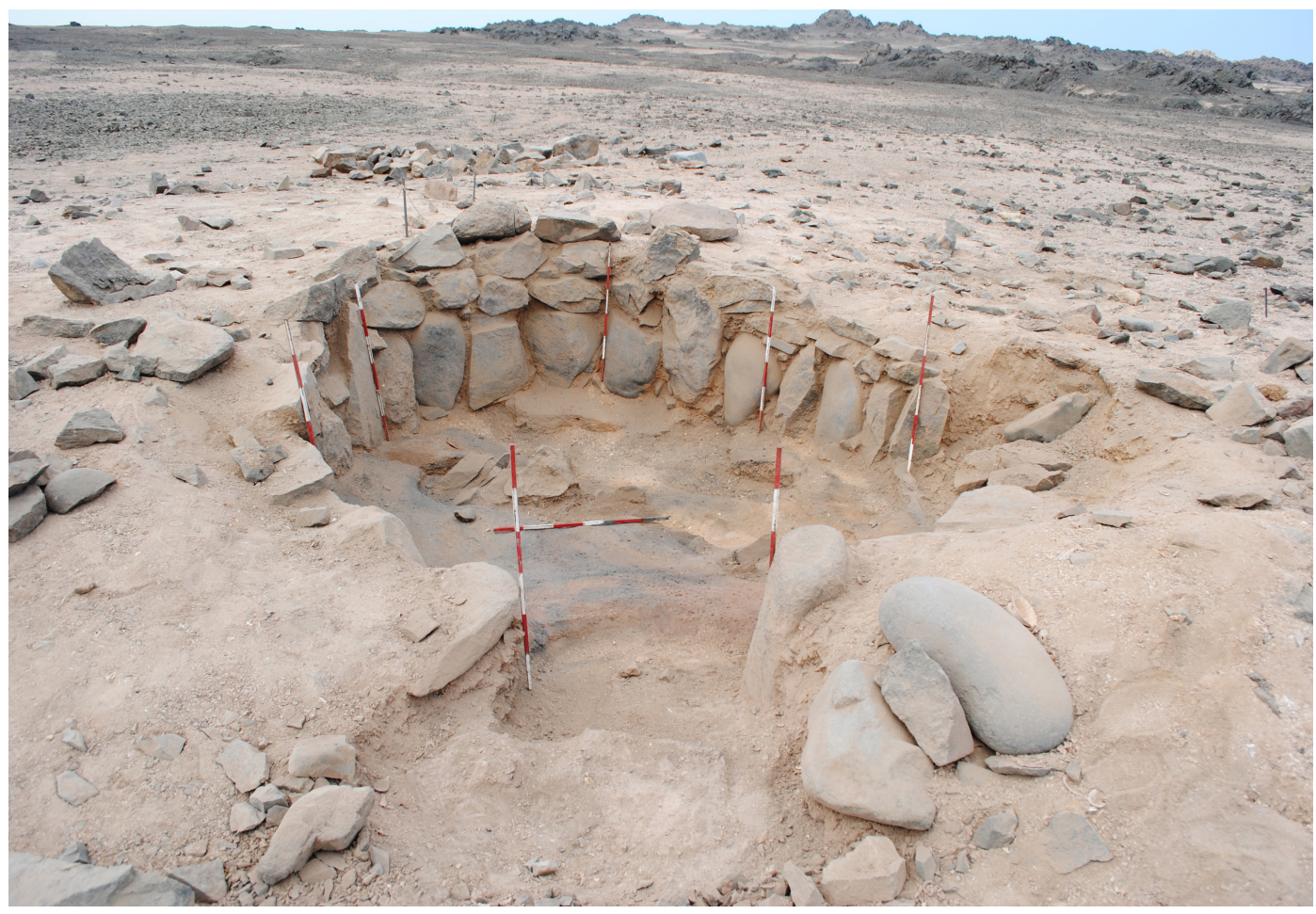

Figura 4. Fotografía de la Estructura 1 luego de su excavación.

Photograph of Structure 1 after the excavation. 
cubriendo el contorno de la cavidad dejada en la excavación subcircular. Las hileras horizontales, por su parte, se encontraban a la altura del conchal exterior, sugiriendo que estas fueron dispuestas a medida que el contorno del recinto se colmaba de basuras. Una vez confeccionados los paramentos, la base del recinto fue cubierta por el mismo mortero utilizado para la sujeción de las lajas verticales, formando un delgado piso preparado (Figura 5). La excavación reveló dos eventos de preparación de pisos, separados por entre 3 y $10 \mathrm{~cm}$ según el sector de la planta, entre los cuales había restos óseos humanos y algunos artefactos. Irrumpiendo entre ambos pisos fueron identificadas además tres fosas o cavidades, una al noroeste, otra al suroeste y otra al centro (Figura 5 y 6 ).

Tal vez el rasgo constructivo más significativo es su vano de acceso, ubicado en el sector noreste del recinto y orientado hacia el espacio central (Figura 4 y $5 \mathrm{~A}$ ). Posee un ancho de $60 \mathrm{~cm}$ y presenta dos jambas, una al lado oeste de $50 \mathrm{~cm}$ de alto y puesta de manera vertical siguiendo la disposición de las lajas del muro, y otra al oriente dispuesta horizontalmente sobre sedimento. El área de acceso presenta además un desnivel a modo de escalón en forma de media luna hacia el interior que no fue recubierto con el mortero del resto del piso, compuesto de un sedimento mucho menos compacto (Figura 6).

Dos elementos constructivos indican una techumbre o toldería. Por un lado, un poste de madera (arbórea) de unos $15 \mathrm{~cm}$ de diámetro quebrado, enterrado verticalmente junto a una de las jambas del acceso, y el segundo, una estaca también de madera tallada en sección cuadrangular con uno de sus extremos en punta incrustada por fuera del muro (Figura 6), posiblemente utilizada como sujeción para los paravientos. El escalón de ingreso y las estacas han sido registrados en otros sitios similares en la costa del desierto de Atacama, en particular en Caleta Huelén 42 (Núñez et al. 1974).

Estos elementos constructivos sugieren una inversión de trabajo colectivo, dirigido no solo a la construcción de los muros, sino también a la excavación de la cavidad, preparación de un suelo formal, disposición de la techumbre con pilares de madera y el abastecimiento de todas las materias
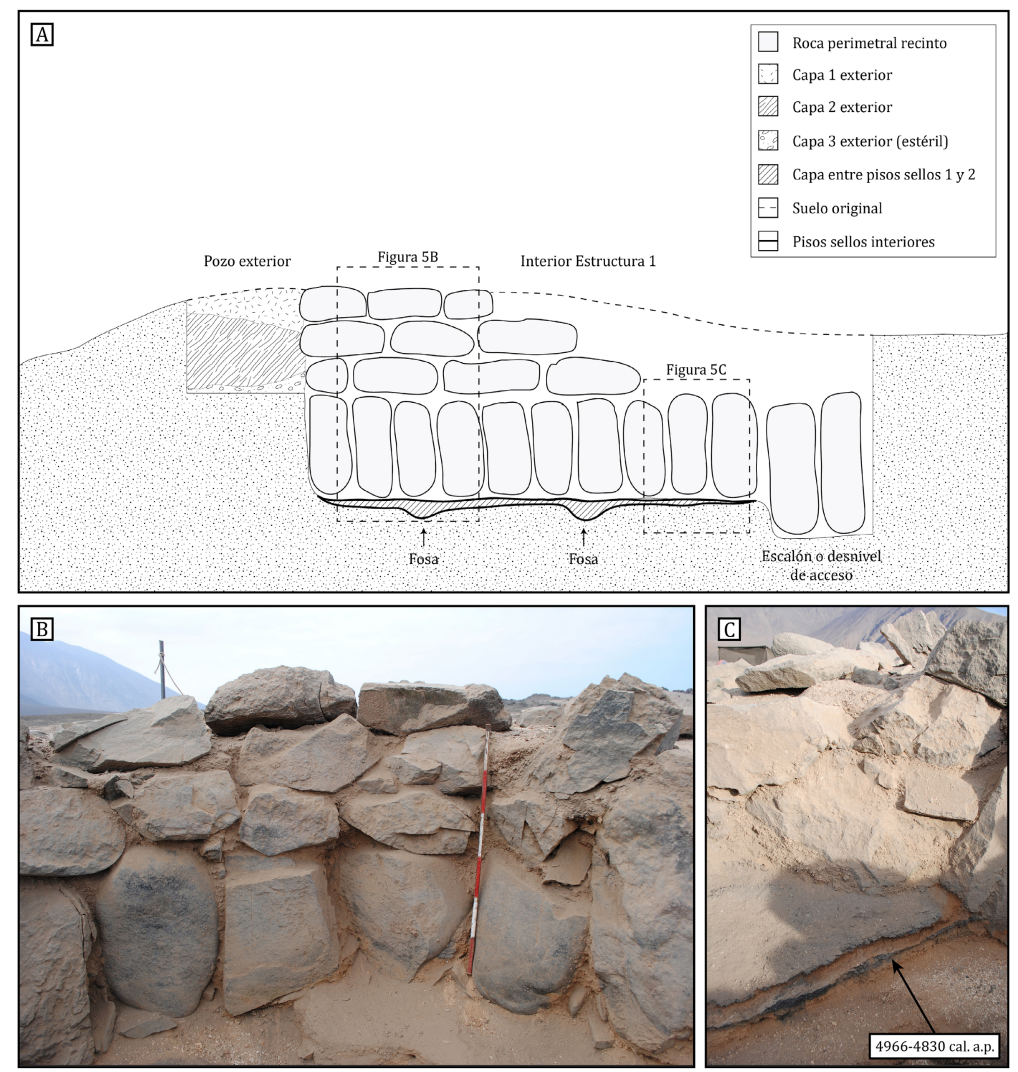

Figura 5. Detalles de la Estructura 1 de AGG-04: (A) Dibujo del corte de perfil de la Estructura 1 y el pozo exterior (eje SW-NE); (B) muro más alto de la estructura (SW) vista desde el interior; (C) dos pisos ocupacionales formales hechos de ceniza.

Details from Structure 1 of AGG-04: (A) Drawing of profile cut of Structure 1 and exterior pit (axe SW-NE); (B) highest wall of the structure $(\mathrm{SW})$ from the inside; $(C)$ two occupational floors with ashes. 

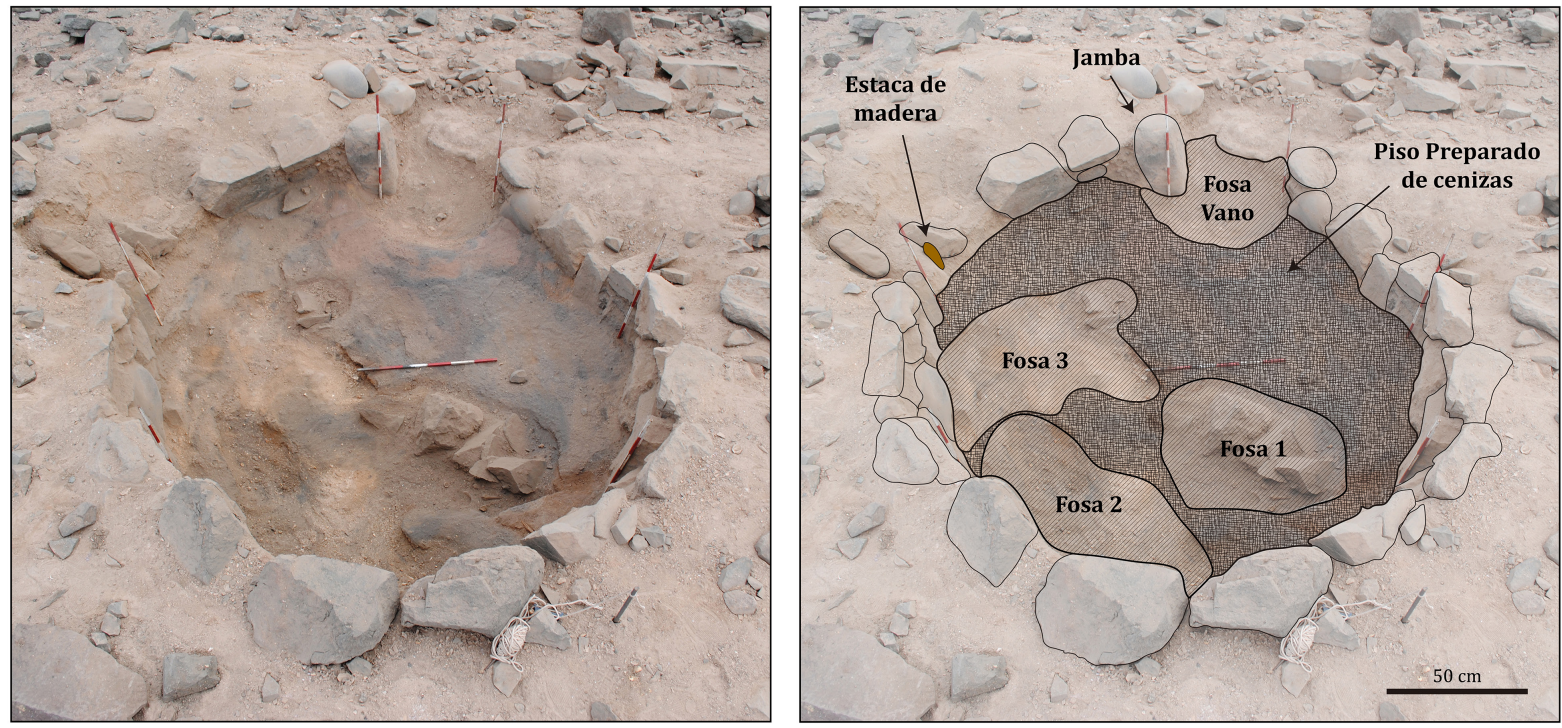

Figura 6: Planta de la Estructura 1 destacando las fosas, piso preparado y algunos elementos arquitectónicos.

Floor plan of structure 1 highlighting the depressions, the prepared floor and some architectural elements.

primas necesarias para su construcción, además de una planificación para ordenar los procedimientos de edificación y permitir arreglos posteriores a su construcción.

\section{Lítica: desechos, materias primas e instrumentos}

La excavación arrojó un total de 2.708 piezas líticas, las cuales fueron analizadas en su totalidad (Andrefsky 1998; Aschero 1983; Aschero y Hocsman 2004; Bate 1971). De estas, 2.625 piezas corresponden a desechos de talla $(96,9 \%)$ y $83(3,1 \%)$ a piezas modificadas (instrumentos, fragmentos o preformas). En términos generales, el material lítico proviene mayoritariamente de actividades de adelgazamiento de instrumentos bifaciales $(60,79 \%)$ y retoque de los mismos (10,32\%), siendo el resto lascas de desbaste de núcleos $(16,59 \%)$ o piezas no determinables $(12,28 \%)$, las que podrían estar asociadas con las fases previas a la producción de bifaces (Tabla 1).

Las materias primas pueden dividirse en dos grupos de acuerdo a su calidad para la talla (Andrefsky 1994; Brantingham et al. 2000): las más numerosas $(95,73 \%)$ fueron de buena calidad (p.e. tobas, ópalos, calcedonias, cuarzos y otras rocas ricas en sílice), donde predominan las de alta calidad $(45,30 \%)$, seguido de las regulares $(36,75 \%)$ y luego las calcedonias $(13,68 \%)$. El segundo grupo de materias primas es de calidad regular a mala, como rocas ígneas no silicificadas de grano medio $(4,27 \%)$, especialmente cantos rodados de playa, utilizados masivamente como instrumentos sobre guijarro de andesitas, dioritas, monzodioritas y granitos (Tabla 1).

La mayoría de los desechos carece de plataforma de percusión, tratándose de fragmentos no proximales de lasca o angulares (50\%). Entre las demás morfologías predominan los talones facetados $(30,4 \%)$ y rebajados $(4,5 \%)$ asociados a lascas de adelgazamiento bifacial, seguidos con menores frecuencias por los talones de morfología plana (14,3\%) derivados de núcleos y a tallado unifacial, y muy pocas plataformas corticales $(0,9 \%)$ (Tabla 2).

En cuanto a la porción de corteza en el dorso de los desechos, prevalecen lascas interiores sin corteza $(83,14 \%)$, mientras que la mayor parte de las que poseen cuentan con entre 0 y $50 \%(12,76 \%)$, pocas con más de $50 \%(4,1 \%)$, sin existir lascas con la totalidad del dorso cubierto de ella. Asociamos su escasa presencia, sobre todo en los desechos de sílice de alta calidad, con el ingreso preferente de matrices bifaciales que habrían tenido un proceso previo de descortezamiento y adelgazamiento, mientras que la presencia de escasas porciones de corteza en sílices de calidad regular y calcedonias, podrían hablar de diversas estrategias de aprovisionamiento y organización tecnológica.

Las dimensiones de los desechos de talla son principalmente de tamaño mediano, entre 7 y $95 \mathrm{~mm}$ (promedio=36 mm). En específico, los desechos de retoque fluctúan entre 6 y $12 \mathrm{~mm}$ ( promedio $=10 \mathrm{~mm}$ ), las lascas de adelgazamiento entre 19 y $92 \mathrm{~mm}$ (promedio $=38 \mathrm{~mm}$ ), las lascas de núcleo entre 12 y $53 \mathrm{~mm}$ (promedio=35 $\mathrm{mm}$ ), 
Tabla 1. Frecuencia y tipos de desechos de talla recuperados de la Estructura 1. Frequency and types of lithic debitage recovered from Structure 1.

\begin{tabular}{|c|c|c|c|c|c|c|c|}
\hline \multicolumn{8}{|c|}{ Desechos de talla } \\
\hline \multirow[b]{2}{*}{$\begin{array}{l}\text { Capa o Rasgo de } \\
\text { excavación }\end{array}$} & \multicolumn{4}{|c|}{ Rica en sílice } & \multirow{2}{*}{\multicolumn{2}{|c|}{$\begin{array}{c}\begin{array}{c}\text { Local no } \\
\text { silícea }\end{array} \\
\begin{array}{c}\text { Lascas y } \\
\text { fragmentos }\end{array}\end{array}$}} & \multirow[t]{2}{*}{ Total } \\
\hline & $\begin{array}{l}\text { Desecho no } \\
\text { determinado }\end{array}$ & $\begin{array}{l}\text { Lasca de } \\
\text { núcleo }\end{array}$ & Adelgazamiento & Retoque & & & \\
\hline Relleno interior recinto & 265 & 297 & 1.378 & 251 & 3 & 103 & 2.297 \\
\hline Justo sobre $1^{\circ}$ piso & 32 & 15 & 60 & 8 & & 4 & 119 \\
\hline $1^{\circ}$ piso, $2^{\circ}$ piso y fosas & & & 22 & & & & 22 \\
\hline Vano de acceso & 18 & 8 & 114 & 12 & & 2 & 154 \\
\hline Bajo vano de acceso & 7 & 6 & 20 & & & & 33 \\
\hline Total & 322 & 326 & 1.594 & 271 & 3 & 109 & 2.625 \\
\hline
\end{tabular}

Tabla 2. Porcentajes de cada tipo de desecho de talla según su tipo de plataforma.

Percentage of every lithic debitage type according to its percussion platform type.

\begin{tabular}{lccccc}
\hline \multicolumn{5}{c}{ Tipo de desecho de talla } \\
\hline Plataforma & Adelgazamiento & Lasca & No determinado & Retoque & Total general \\
\hline Plana & $12,5 \%$ & $0 \%$ & $0 \%$ & $2,7 \%$ & $15,2 \%$ \\
\hline Facetado & $29,5 \%$ & $0 \%$ & $0 \%$ & $0,9 \%$ & $30,4 \%$ \\
\hline Rebajado & $4,5 \%$ & $0 \%$ & $0 \%$ & $0 \%$ & $4,5 \%$ \\
\hline Ausente & $7,1 \%$ & $9,8 \%$ & $29,5 \%$ & $3,6 \%$ & $50 \%$ \\
\hline Total general & $53,6 \%$ & $9,8 \%$ & $29,5 \%$ & $7,1 \%$ & $100 \%$ \\
\hline
\end{tabular}

mientras que los no determinables entre $10 \mathrm{~mm}$ y $55 \mathrm{~mm}$ (promedio=32 $\mathrm{mm}$ ). Respecto al tipo de instrumentos producidos en base a los desechos de talla analizados se infiere que se trató de hojas bifaciales para la producción de cuchillos o cabezales. El gran tamaño de las lascas de adelgazamiento y su masividad apoyan esta hipótesis. El conjunto de desechos muestra en general la completa ausencia de las etapas iniciales de preparación de bifaces y su reducción-apoyado por la baja frecuencia de corteza en los anversos-; están presentes solo desde las etapas medias a finales de la cadena operativa, no así aquellas de los artefactos más toscos sobre materias primas locales, cuyas cadenas operativas se encuentran completas en el sitio.

Entre los instrumentos más interesantes (Figura 7.1 a 7.7) se encuentra un cabezal lítico de tipo lanceolado con pedúnculo corto y angosto, con cintura a ambos costados en su tercio proximal (Figura 7.1), ofrendado a un entierro en la Fosa 1 del piso ocupacional. En la excavación de la capa entre el primer y segundo piso preparado de la estructura, se encontró un cuchillo cuyo diseño cuenta con una acanaladura que cubre casi toda la cara, junto a retoques marginales en ambos bordes activos (Figura 7.4). Las materias primas utilizadas coinciden con los desechos de talla.

Las piezas líticas formatizadas completas, salvo las descartadas, fueron todas encontradas en la base de la estructura, ya sea en el piso superior, entre los pisos preparados o en la oquedad del vano de acceso; todos probablemente depositados como ofrenda al evento fundacional de la estructura y a los entierros humanos (Tabla 3). Los $70 \mathrm{~cm}$ de depósito superior están compuestos por desechos de talla, fragmentos de instrumentos, piezas no finalizadas (preformas) e instrumentos sobre guijarros, definiéndola como una ocupación con actividades de talla in situ para la fabricación de artefactos de corte y caza, algunos de los cuales fueron además utilizados y descartados en el mismo sitio (p.ej. cuchillos).

\section{Fauna: restos esqueletales, valvas de moluscos y parches de recursos}

Se recuperó un total de 1.387 restos óseos, de los cuales $691(49,8 \%)$ pudieron ser identificados anatómica y taxonómicamente (Tabla 4). Entre estos últimos, los peces son los más representados $(85,5 \%)$, destacando dos especies por su alta frecuencia (Tabla 4): Trachurus murphyi (jurel) y Cilus gilberti (corvina). Estos peces corresponden a especies pelágicas que se mueven en grandes cardúmenes que pueden ser capturados con redes desde la costa o una embarcación, o bien con anzuelos y líneas de pesca. Las otras especies identificadas (Tabla 4) 

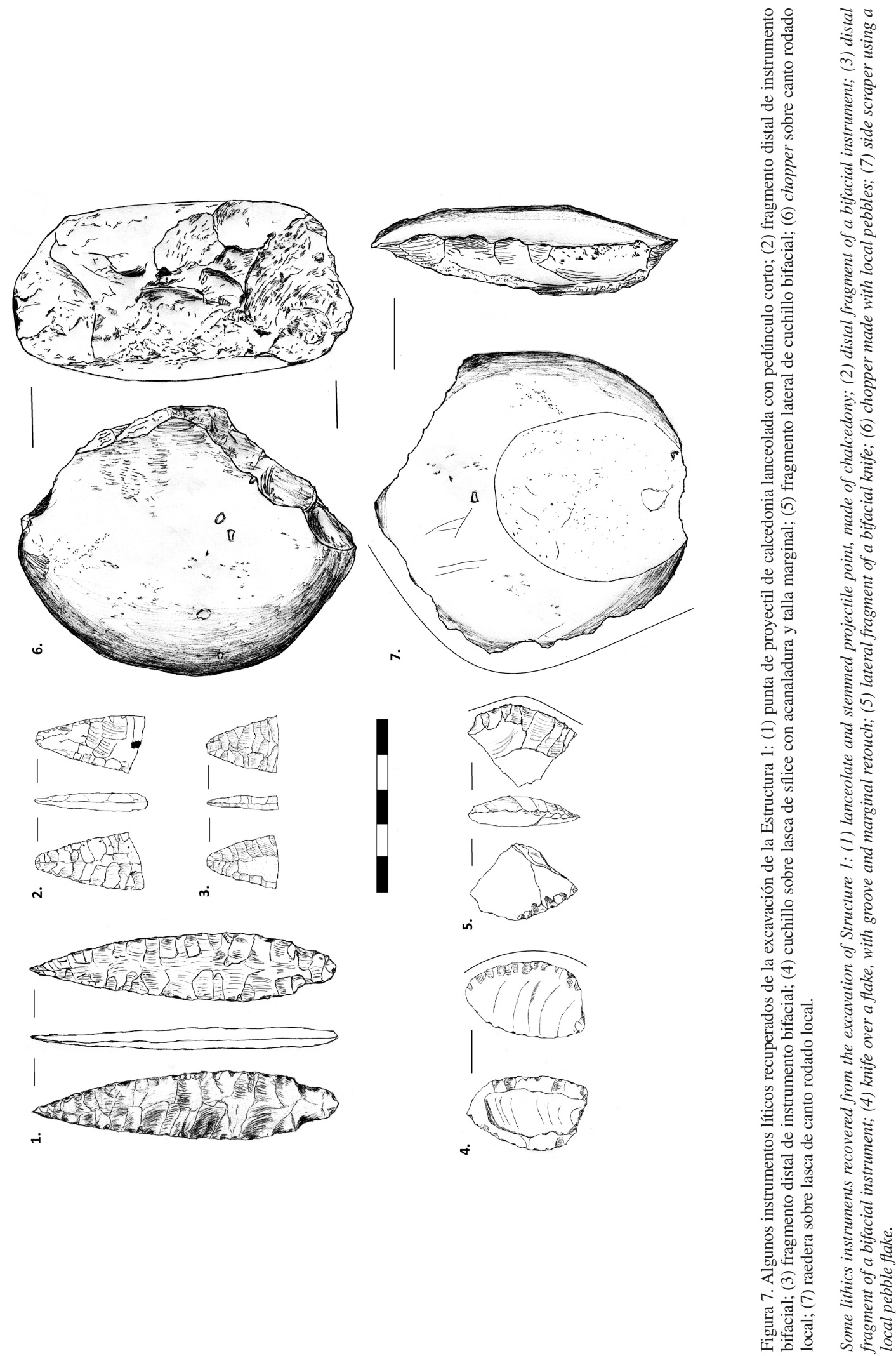
Tabla 3. Frecuencia de tipos de instrumentos líticos recuperados de la Estructura 1. Frequency of types of lithic instruments recovered from Structure 1.

\begin{tabular}{|c|c|c|c|c|c|c|c|}
\hline \multirow[b]{3}{*}{$\begin{array}{l}\text { Capa o Rasgo de } \\
\text { excavación }\end{array}$} & \multicolumn{6}{|c|}{ Instrumentos } & \multirow{3}{*}{$\begin{array}{c}\text { Local no } \\
\text { silícea }\end{array}$} \\
\hline & \multirow[b]{2}{*}{$\begin{array}{l}\text { Cuchillo } \\
\text { sobre lasca }\end{array}$} & \multirow[b]{2}{*}{$\begin{array}{l}\text { Cuchillo } \\
\text { bifacial }\end{array}$} & \multicolumn{2}{|c|}{ Rica en sílice } & \multirow[b]{2}{*}{ Raspador } & \multirow[b]{2}{*}{ Muesca } & \\
\hline & & & $\begin{array}{c}\text { Preforma } \\
\text { bifacial }\end{array}$ & $\begin{array}{l}\text { Punta de } \\
\text { proyectil }\end{array}$ & & & \\
\hline Relleno interior recinto & 9 & 1 & 17 & & 2 & & 19 \\
\hline Sobre $1^{\circ}$ piso & 4 & & 2 & 2 & 1 & 1 & 17 \\
\hline \multicolumn{8}{|l|}{$1^{\circ}$ piso, $2^{\circ}$ piso y fosas } \\
\hline Vano de acceso & 3 & & 3 & & & & \\
\hline Bajo vano de acceso & 2 & & & & 1 & & 1 \\
\hline
\end{tabular}

corresponden en su mayoría a peces de ambientes rocosos, cuya captura seguro se realizó mediante arpones y/o anzuelos, aunque también se registra una especie de fondos arenosos (Sciaena deliciosa) (Tabla 4).

Los restos de mamíferos son escasos $(7,5 \%)$, principalmente camélidos, otáridos, delfínidos y roedores cricétidos (Tabla 4). Los más abundantes son los restos de camélido, entre los que se identificaron unidades del esqueleto axial (fragmentos de cráneo, vértebras y costillas) como apendicular, las que permitieron determinar la presencia de al menos dos

Tabla 4. Frecuencia de restos óseos animales recuperados de la Estructura 1.

Frequency of faunal bone remains recovered from Structure 1.

\begin{tabular}{|c|c|c|c|}
\hline & NISP & MNE & MNI \\
\hline Acanthistius pictus & 15 & 15 & 1 \\
\hline Cheilodactylus variegatus & 20 & 20 & 2 \\
\hline Chondrichthyes & 23 & 23 & 2 \\
\hline Cilus gilberti & 40 & 40 & 10 \\
\hline Graus nigra & 3 & 3 & 1 \\
\hline Pinguipes chilensis & 1 & 1 & 1 \\
\hline Sciaena deliciosa & 1 & 1 & 1 \\
\hline Semicossyphus maculatus & 10 & 10 & 2 \\
\hline Sicyases sanguineus & 8 & 8 & 2 \\
\hline Trachurus murphyi & 183 & 171 & 24 \\
\hline Pez Indet. & 287 & 214 & 21 \\
\hline Camelidae & 26 & 19 & 2 \\
\hline Delphinidae & 6 & 3 & 1 \\
\hline Otariidae & 8 & 8 & 2 \\
\hline Cricetidae & 12 & 12 & 2 \\
\hline Pelecanus sp. & 14 & 13 & 2 \\
\hline Phalacrocorax sp. & 4 & 4 & 1 \\
\hline Ave grande & 1 & 1 & 1 \\
\hline \multirow[t]{2}{*}{ Ave mediana } & 29 & 28 & 4 \\
\hline & 691 & 594 & 82 \\
\hline
\end{tabular}

individuos, uno menor y otro mayor a 30 meses de edad (Kaufmann 2008). No fue posible obtener datos métricos de los restos de camélido para establecer comparaciones taxonómicas. Sin embargo, aún habitan pequeñas poblaciones aisladas de guanacos (Lama guanicoe) en la cordillera de la costa del desierto de Atacama (Bittmann 1986; Oltremari et al. 1987), un remanente de una dispersión costera mucho más extendida (González et al. 2006). Entre estos restos se registró una primera falange con huellas de corte y dos instrumentos, un posible retocador elaborado sobre la diáfisis de un radio ulna y una barba de arpón.

Los restos de otáridos y delfínidos son mucho más escasos (Tabla 4). Para los primeros se registraron fragmentos de vértebra, esternón, húmero, metapodio y falanges, provenientes de al menos dos individuos, mientras que para los delfínidos solo se identificaron cuerpos y discos vertebrales. Por último, los restos de roedores cricétidos evidencian la presencia de al menos dos individuos de pequeño tamaño, posiblemente intrusivos.

El grupo de las aves es el menos representado $(6,9 \%)$, identificándose solo dos especies marinas locales, Pelecanus thagus (pelícano) y Phalacrocorax sp. (cormorán). Entre los restos de pelícano se registró un fragmento de ulna con huellas de corte, mientras que en los de cormorán un fragmento de coracoides exhibe huellas de roído, lo que apoya que los roedores pudieron ingresar atraídos por el basural.

En general se observa un número reducido de restos con evidencia de combustión o algún otro tipo de modificación, lo que indicaría que su descarte y entierro en el conchal fue más rápido. Además, la mayor parte de ellos (74\%) fueron recuperados de la unidad de excavación realizada al exterior, demostrando hábitos de limpieza de los recintos habitacionales y una alta intensidad de pisoteo.

Para el análisis malacológico se realizó la identificación taxonómica de la totalidad de los 
restos recuperados tanto del interior del recinto como del pozo de sondaje exterior. Debido al alto grado de fragmentación y meteorización la cuantificación se realizó pesando la totalidad de las valvas por especie para tener una visión comparativa de la frecuencia de cada una de ellas dentro del conjunto (Claassen 2000; Glassow 2000). Se identificaron ocho taxones a nivel de especie y dos a nivel de género a partir de analogías con colecciones de referencia. En un total de 33.119 gr de restos malacológicos, el $98,5 \%$ de la masa corresponden a valvas de moluscos que habitan en ambientes rocosos, mientras que solo un 1,2\% proviene de playas arenosas (Figura 8). Si bien esta última cifra es reducida, demuestra la presencia de moluscos no inmediatos al sitio y provenientes de playas fuera de la bahía de Gualaguala (Figura 1).

Respecto de la integridad del contexto malacológico, el interior del recinto presentó un grado de fragmentación y meteorización muchísimo más alto que el exterior, relacionado probablemente con actividades de pisoteo y circulación.

La presencia de valvas de Oliva peruviana y Argopecten purpuratus, por su baja frecuencia en el depósito (Figura 8), pudieron ser transportadas al sitio no como alimento sino a modo de materia prima para la confección de artefactos. Una situación similar pudo ocurrir con las valvas de Choromytilus chorus, presentes en su mayoría en el pozo de sondaje al exterior de la estructura y con sus conchas en un estado de mejor conservación respecto al resto de las especies.

\section{Bioantropología: conviviendo junto a los muertos}

Durante las excavaciones se registraron restos óseos de al menos seis humanos ubicados en distintos niveles estratigráficos y sectores de la planta habitacional. El primero se encontraba en el costado oeste del recinto, varios centímetros sobre el piso sello y cubierto por un amontonamiento de rocas de distintos tamaños, algunas de las cuales habían sido extraídas del muro perimetral. Estaba en un sedimento más mezclado y suelto que el resto de la estructura, sugiriendo que se trataba de un entierro intrusivo de momentos posteriores al abandono del recinto. El cuerpo estaba dispuesto en posición decúbito lateral e incompleto -seguro producto de la actividad de saqueadores-, presentando únicamente restos de tórax, columna, miembros superiores e inferiores, cintura pélvica y escapular, huesos de mano y pies (Figura 9). Su edad biológica -a juzgar por el estado de fusión de las vértebras

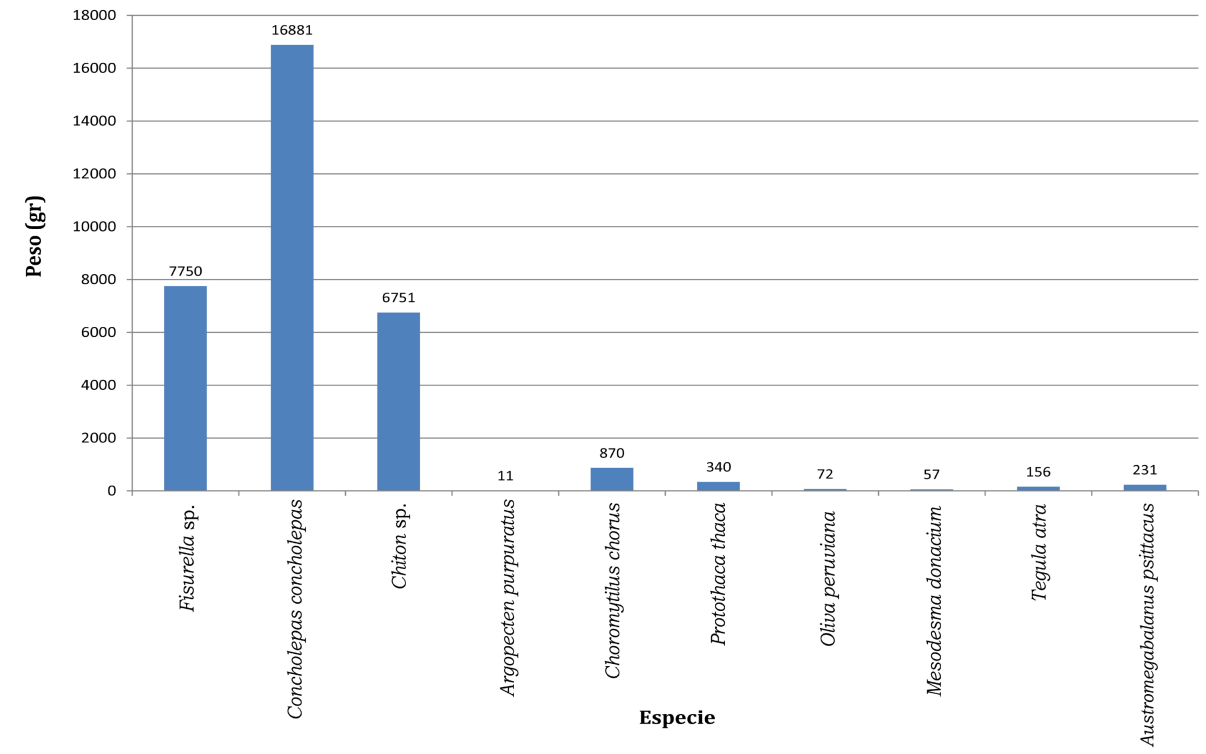

Figura 8. Frecuencia en peso de moluscos recuperados de la Estructura 1.

Weight of mollusks frequency recovered from Structure 1. 
sacrales S1 y S2- oscila entre los 20 a 25 años (Schaefer et al. 2009; Scheuer y Black 2000). La preservación de sus coxales impidió estimar sexo. En términos generales, las articulaciones presentan severos niveles de osteoartritis y las entesis notorios grados de calcificación, signos que en un individuo joven obligan a considerarlos como marcas de estrés músculo-esqueletal derivadas de sobreexigencia biomecánica. Entierros intrusivos en este tipo de estructuras habitacionales han sido documentados también en otros sitios de la región, interpretados como causa de la reutilización y continuidad ocupacional de los recintos (Ballester et al. 2014b; Núñez et al. 1974).

A la altura del piso ocupacional superior y en distintos sectores de este se identificaron tres fosas o cavidades diferenciadas entre sí que contenían restos óseos humanos y ofrendas (Figura 5 y 6). La Fosa 1 contenía restos de un individuo adulto (mayor de 20 años) de sexo indeterminado e incompleto, compuesto de un radio izquierdo, un calcáneo derecho, cuboide izquierdo, trapecio derecho, fragmento de costilla y otros restos óseos fragmentados de mano, pie y miembros superiores. No siendo posible estimar un rango etario preciso, desconocemos si los severos rasgos de osteofitosis articular en el calcáneo están asociados a sobrecarga mecánica o a senescencia. El radio exhibe signos de pitting, que similar al calcáneo, puede ser resultado de procesos degenerativos o ser derivado de sobreexigencias mecánicas producidas por actividad física. Asociado directamente al entierro como ofrenda fue recuperado un fino cabezal lítico de forma ojival y pedúnculo en forma de botón (Figura 7.1) junto a un choppe hecho sobre un guijarro (Figura 7.6).

En la segunda fosa se registraron restos óseos de dos individuos incompletos, uno perinatal -probablemente prenatal- de 38 semanas de gestación (calculado según el largo máximo del húmero izquierdo: $5,96 \mathrm{~cm}$ ) (Fazekas y Kósa 1978) y otro adulto, mayor a 20 años de edad. Este último preserva talus izquierdo, calcáneo izquierdo, navicular de pie derecho, huesos cuneiformes del pie derecho, fragmento de costilla, fragmento de vértebra torácica y dos molares. El tercer molar tiene un desgaste leve que solo exhibe algunos puntos de dentina en sus cúspides. Los huesos del pie tienen osteoartrosis severa.

La tercera fosa presentaba restos óseos de un individuo completo, de desarrollo perinatal, específicamente de 40 semanas de gestación (calculado según el largo máximo del fémur derecho: $7,49 \mathrm{~cm}$ ) (Fazekas y Kósa 1978). Sus huesos largos presentan periostitis.

En el sector del vano de acceso y sobre el desnivel de mayor profundidad o escalón (Figura 5 y 6), se recuperaron restos esqueletales de un individuo adulto incompleto de más de 20 años de edad, compuesto de cuerpos vertebrales, un talus o astrágalo de pie izquierdo, metacarpo de la mano izquierda, dos falanges proximales de pie y mano, un segundo molar, un premolar y un canino. El grado de desgaste dentario expone dentina en los dos primeros y en el canino la pulpa, demostrando prácticas alimentarias que implican desgarre de alimentos, esperable en grupos cazadores recolectores (Smith 1984). Asociado a este individuo había un bloque de piedra $(30 \times 17 \mathrm{~cm})$ con incisiones alargadas a modo de líneas o rayas sobre una de sus caras (Figura 10), un rasgo muy característico para este momento temporal entre las poblaciones litorales y considerado como expresiones de arte rupestre móviles e inmuebles vinculados a estos espacios arquitectónicos y como ofrenda en los contextos fúnebres (Ballester y Gallardo 2011; Contreras et al. 2008, 2011; Mostny 1964; Núñez 2016; Núñez y Contreras 2011). Otros bloques similares fueron registrados en los alrededores del sitio.

\section{Cronología}

Desde el primer piso de cenizas -o inferior(Figura 5C) se tomó una muestra de carbón para fechado por AMS que dio como resultado $4350 \pm 30$ AP, lo que calibrado en dos sigmas con la curva SHCAL 13 (Calib Rev 7.0.4) arroja un rango entre 4966-4830 cal. AP (Beta-352200; 13C/12C (o/ oo $)=-12,4)($ Hogg et al. 2013; Stuiver et al. 2005).

\section{Inmuebles, Centralización y Convivencia con los Ancestros: Tres Ejes de la Reducción de la Movilidad Residencial}

Los depósitos habitacionales del conglomerado, tanto del interior del recinto como en su exterior, permiten definirlo como un campamento residencial. El análisis de las basuras de fauna demuestran el consumo y descarte de una enorme diversidad de especies marinas y terrestres -al menos 11 de peces, dos de mamíferos marinos, un mamífero terrestre, un roedor, cuatro aves y 10 moluscos (Figura 8, Tabla 4)provenientes buena parte de ellos de microambientes distintos al área de emplazamiento del campamento (recordemos que se encuentra a $800 \mathrm{~m}$ de la línea de costa). Esto implica una estrategia en la cual recursos explotados en un vasto territorio fueron transportados hacia el campamento residencial para su consumo.

Desde los moluscos se aprecia una intensa explotación del intermareal rocoso, posiblemente de Gualaguala y otros cercanos (p.ej. Concholepas concholepas, Fisurella sp., Chiton sp., Tegula atra), 

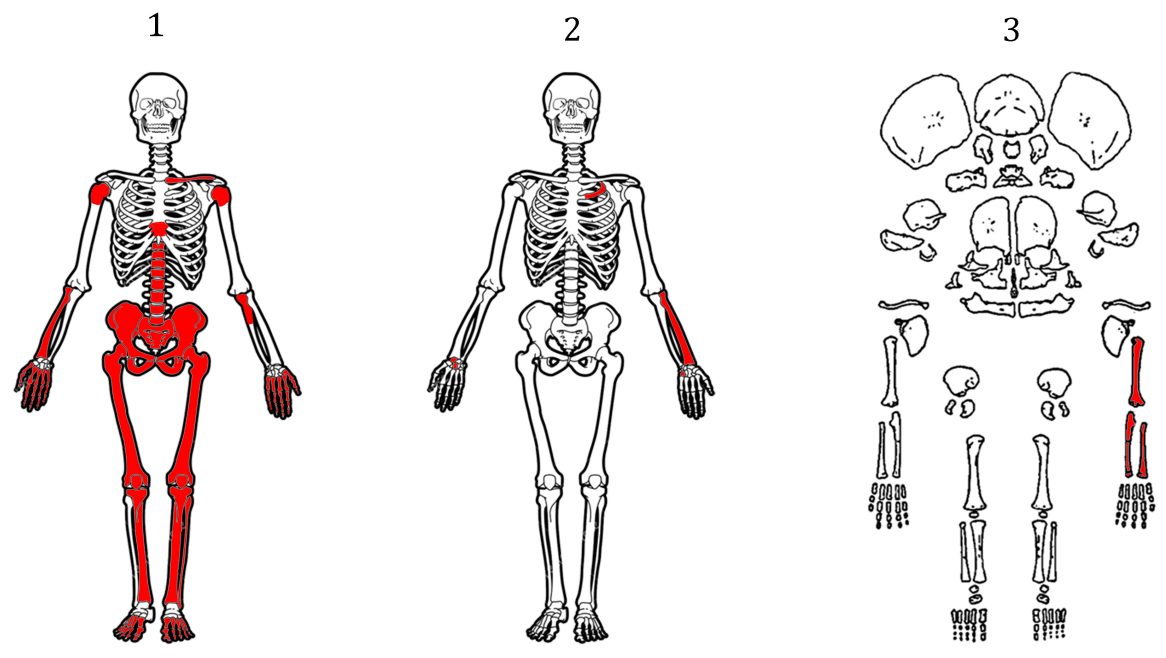

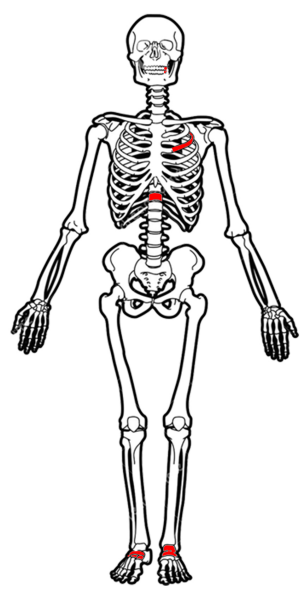

4

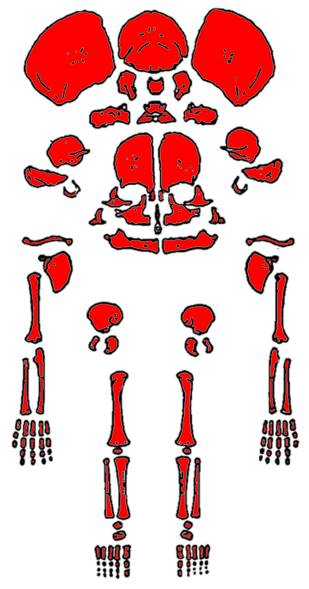

5

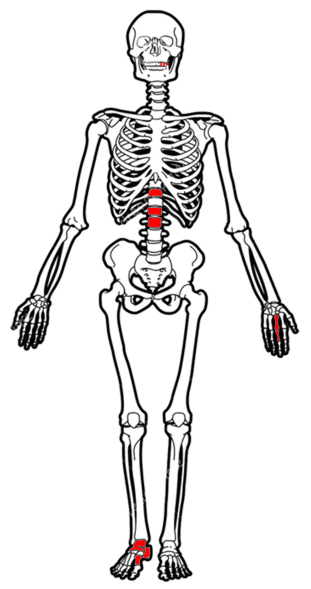

6

Figura 9. Detalle de los elementos esqueletales presentes (en rojo) de cada individuo en la Estructura 1: (1) entierro intrusivo sobre el piso ocupacional; (2) restos esqueletales en la fosa 1; (3) individuo perinatal de la fosa 2; (4) individuo adulto de la fosa 2; (5) individuo perinatal completo de la fosa 3 ; (6) individuo en cavidad del vano de acceso.

Detail of skeletal elements presents (in red) in every individual in Structure 1: (1) intrusive burial above the occupational floor; (2) skeletal remains in pit 1; (3) perinatal individual from pit 2; (4) adult individual from pit 2; (5) complete perinatal individual from pit 3; (6) individual found in the doorway cavity. 


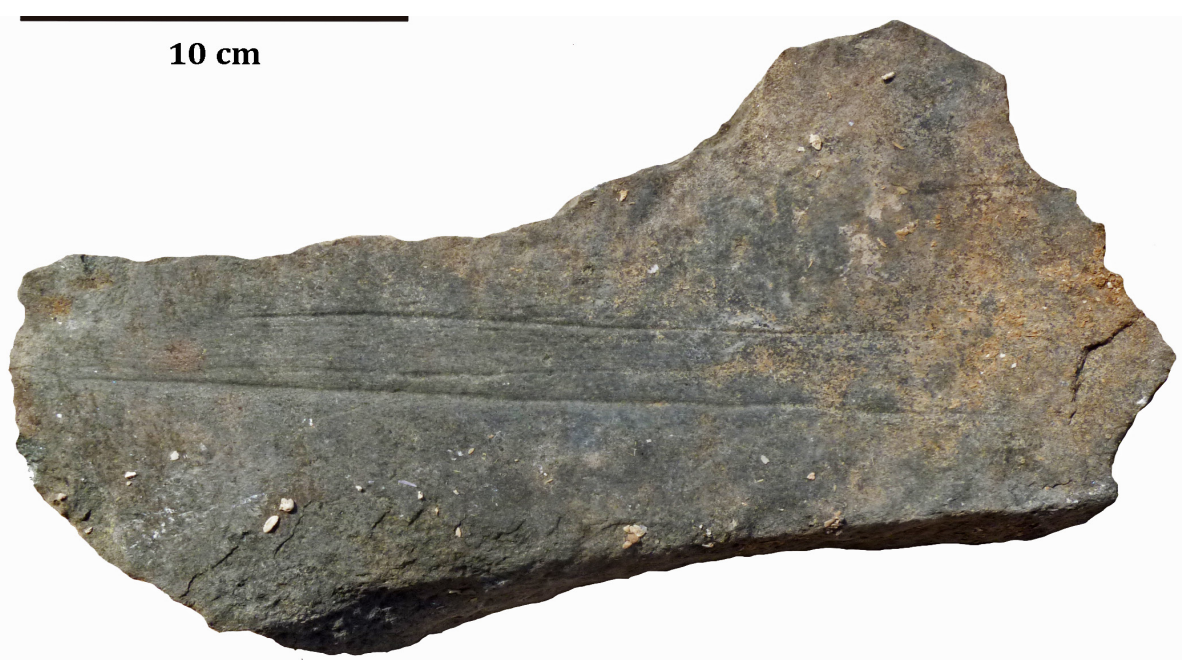

Figura 10. Bloque de roca con incisiones lineales en una de sus caras principales encontrado dentro de la cavidad del vano de acceso. Rock block with lineal incisions in one of their principals faces, found inside the access opening.

aunque también de ambientes de playas arenosas (p.e. Mesodesma donacium, Protothaca thaca) no inmediatas a la bahía, como Mejillones ( 35 $\mathrm{km})$, Hornitos $(\sim 10 \mathrm{~km})$ o Michilla $(\sim 4,5 \mathrm{~km})$. El abastecimiento de Argopecten purpuratus y Choromytilus chorus implican el uso de técnicas de buceo para capturar individuos vivos, y en caso de transportarse como materia prima para la confección de artefactos, una movilidad dirigida hacia las fuentes de disponibilidad de estas valvas, sea en formaciones paleontológicas, otros sitios arqueológicos o varazones ocasionales.

Una situación similar se observa para la fauna vertebrada, pues involucran distintos microambientes: mamíferos de tierra firme (camélidos) y marinos (otáridos y delfínidos), peces del intermareal rocoso (p.e. Acanthistius pictus, Cheilodactylus variegatus, Graus nigra, Semicossyphus darwini, Sicyases sanguineus), de ambientes más arenosos (p.ej. Sciaena deliciosa), algunos bentónicos (Pinguipes chilensis) y pelágicos (Cilus gilberti, Trachurus murphyi), acompañados de aves marinas. Si bien parte de ellos pudieron ser obtenidos en las inmediaciones del sitio, el abastecimiento de otros se produjo necesariamente en zonas más alejadas, sea en el interior del desierto o mar adentro, en colonias de lobos o de aves, para luego ser transportados al centro habitacional para su distribución y consumo grupal. El análisis de las piezas esqueletales mostró que las presas de mayor tamaño, como otáridos, delfínidos y camélidos se encuentran incompletos, resultado de un transporte diferencial de unidades anatómicas al sitio; capturados y faenados en otras locaciones logísticas ubicadas en distintos microambientes, demostrando el uso campamentos de tareas distantes vinculados a la caza y faenamiento de animales.

La industria lítica lleva a interpretaciones similares sobre su estructura de asentamiento y movilidad. Dos paisajes líticos fueron los preferidos por los habitantes de Gualaguala. Por un lado a lo largo de la terraza litoral accedieron a materias primas como andesitas, dioritas y granitos disponibles en forma de guijarros o clastos angulares, utilizados principalmente para manufacturar artefactos toscos como chopper, chopping tools, percutores, sobadores de cuero y manos de moler, una estrategia común a otros sitios litorales (p.ej. Ballester et al. 2014a; 2014b; Berdichewski 1965; Bird 1943, 1965; Capdeville 1928; Castro et al. 2016; García-Albarido 2012; Latcham 1939; Mostny 1964; Núñez et al. 1974; Oyarzún 1916; Salazar et al. 2015; Uhle 1916, 1917).

Por el otro lado se encuentra la industria bifacial ampliamente necesaria en una población que subsiste gracias a la caza y la pesca, en especial para la confección de cuchillos de distintos tamaños y formas empleados en las tareas de faenamiento y trabajo de materias blandas animales (cueros, tendones), además de las puntas de proyectil (caza). Esta industria se sustenta en materias primas no locales accesibles únicamente desde la cordillera de la costa hacia la depresión intermedia, en extensas fuentes secundarias o campos de calcedonias y rocas ígneas altamente silicificadas, distantes 
de la costa en un rango que va desde los 20 a los $120 \mathrm{~km}$ hacia el interior del desierto (Ballester y Crisóstomo 2017; Blanco et al. 2010; Borie et al. 2017; Le Paige 1970; Mostny 1964; Núñez 1984; Peralta et al. 2010; Uhle 1916, 1917; Urrejola y Orellana 2000). Las cadenas operativas de los artefactos manufacturados sobre estas materias primas muestran una primera etapa de trabajo que fue realizado cercano a las fuentes, generando bases bifaciales con bajo porcentaje de corteza a modo de soportes, las que eran transportadas hacia los campamentos residenciales en la costa donde continuaba el proceso de reducción de los bifaces hasta su finalización en instrumentos como distintos tipos de cuchillos, cabezales de dispositivos de caza, raspadores, cepillos, buriles, entre otros. Los desechos generados en los campamentos residenciales fueron también aprovechados para la manufactura de otros instrumentos como cuchillos de filo natural o de retoque marginal, perforadores, raspadores, puntas de proyectil y cuñas.

En conjunto puede apreciarse una lógica de abastecimiento lítico de carácter logístico que requería de campamentos de tarea en la pampa, rutas pedestres definidas y el amplio conocimiento del paisaje lítico interior (Ballester y Crisóstomo 2017; Ballester y Gallardo 2011; Blanco 2013; Blanco et al. 2010, 2017; Borie et al. 2017; Pimentel et al. 2011; Uhle 1916, 1917). La producción generada era luego importada hacia los campamentos residenciales donde continuaba la tarea de reducción bifacial, mientras que los instrumentos terminados eran transportados hacia las áreas de trabajo en las actividades de caza, pesca y faenamiento de los animales.

En cuanto a la arquitectura, durante el período Arcaico Tardío nos encontramos frente a las primeras manifestaciones de una producción habitacional inmueble en el litoral (Llagostera 1989, 2013; Núñez 1999; Salazar et al. 2015; True 1975). Bienes construidos para no ser desplazados y arraigados al territorio, sobre los que se invirtió importantes esfuerzos grupales. Si bien la mayor parte de los materiales de construcción estaban disponibles localmente, el proceso de selección, recolección, transporte, construcción y mantención involucró trabajos colectivos y un acabado conocimiento del paisaje y sus recursos. Los pilares fundacionales de las estructuras fueron seleccionados según forma y tamaño; cada estructura exigió la preparación de la superficie, excavando el sedimento para empotrar las lajas de los muros; la preparación del mortero involucró la extracción de vegetales que posteriormente fueron quemados y mezclados con otros materiales, como arena, agua, conchas y posiblemente otro tipo de desechos. Todos estos procesos apuntan a la existencia de ciertas recetas $\mathrm{y}$ formas de hacer que conectan lugares, prácticas, experiencias y personas en el acto constructivo, lo cual ciertamente requirió la coordinación de labores y trabajo como parte de un proyecto a través del cual se generaron y actualizaron lazos colectivos (Harris 2014). A la vez, las prácticas de cuidado de estos sitios -mantención de los espacios interiores a través de la limpieza, tratamiento de los muertos, cuidadosa construcción de los recintos- apuntan a la existencia de ciertos vínculos afectivos entre personas y lugares que se reforzaban socialmente por medio de la arquitectura (Roddick 2013; Roddick y Stahl 2016). La presencia de distintas subunidades distinguidas formalmente mediante muros -recintos- muestra que si bien la comunidad convivía en un espacio común -conglomerado-, esta se encontraba dividida internamente en subunidades -habitaciones-. La existencia de un espacio central al que confluyen los vanos de acceso de los distintos recintos del complejo materializa los vínculos necesarios entre cada una de ellas en lo cotidiano.

Este tipo de arquitectura no es exclusiva de este asentamiento. Por el contrario, reconocemos que es sumamente común a lo largo del litoral al menos desde el norte de la desembocadura del río Loa hasta el sur de Taltal dentro del lapso temporal comprendido entre los 6500 y $4000 \mathrm{cal}$. a.p., emplazadas especialmente junto a aguadas y bahías abrigadas (Ballester et al. 2014a; 2014b; 2017; Bittmann 1984; Castro et al. 2016; Contreras et al. 2008; 2011; Llagostera 1989, 2013; Mostny 1964; Núñez et al. 1974; Salazar et al. 2015; Zlatar 1983, 1989). Las similitudes constructivas y de planificación infraestructural en la edificación son notables, conformando una misma tradición cultural que excedía la esfera arquitectónica y espacial también hacia el ámbito de las tecnologías de pesca y caza marina, con diseños, estrategias y dispositivos comunes (Ballester y Gallardo 2011; Ballester et al. 2017; Llagostera 1989).

Dentro de los límites del recinto, sus ocupantes dispusieron bajo sus pisos restos de al menos cinco personas, entre perinatales y adultos, junto a ofrendas como un cabezal lítico bifacial, una barba de arpón y bloques con incisiones lineales. Prácticas que fueron producto del proceso de construcción de este espacio, utilizando los cuerpos de los difuntos como un insumo de alto valor y significación social, lo que creaba un vínculo filial entre sus habitantes, aquellos que descansaban bajo las habitaciones y quienes llevaron a cabo el rito fúnebre, para generar una estrecha relación entre humanos, ancestros y localidad (Barret 1990; Brown 1995; Huntington y 
Metcalf 1979; Morris 1991). Este fenómeno resulta aún más significativo si consideramos que estos entierros corresponden a los primeros espacios fúnebres colectivos de la secuencia del litoral del desierto de Atacama, llegando a albergar en algunos casos - $\mathrm{CaH}$ 42- fragmentos de hasta 18 individuos bajo el piso de un solo recinto (Andrade et al. 2016; Ballester et al. 2017; Contreras et al. 2008; Mostny 1964; Núñez et al. 1974; Zlatar 1983, 1989).

Los resultados preliminares presentados en este breve reporte de sitio, al ser evaluados al alero de la prehistoria local, nos permiten sostener que durante este período pudieron consolidarse simultáneamente tres manifestaciones sociales: las primeras evidencias de inmuebles de uso y edificación colectiva, la posición de estos espacios como nodos en los que se concentra la producción generada en un amplio territorio, y la utilización del cuerpo de los ancestros para fundar las habitaciones, dotando de un valor filial y simbólico a estos espacios de residencia y consumo. Tres facetas de un mismo fenómeno social, tres manifestaciones materiales de un proceso a través del cual las poblaciones costeras establecieron lazos históricos entre sí y con el espacio en el que habitaban, teniendo a la vez como resultado y causa la reducción de su movilidad residencial producto de una nueva forma de organización social y patrón de asentamiento (Ballester y Gallardo 2011).

Agradecimientos: ProyectosFONDECYT 1110702 y 1160045, FONDAP 15110006. A David Torres-Rouff. Agradecemos los comentarios de los evaluadores y la labor editorial de la revista. Permiso del CMN $\mathrm{N}^{\circ} 2250 / 12$ del 30/05/2012.

\section{Referencias Citadas}

Ames, K. 1981. The evolution of social ranking on the Northwest Coast of North America. American Antiquity 46:789-805.

Ames, K. 1995. Chiefly power and household production on the Northwest Coast. En Foundations of Social Inequality, editado por D. Price y G. Feinman, pp. 155-187. Plenum Press, New York.

Ames, K. 2001. Slaves, chiefs and labour on the Northern Northwest Coast. World Archaeology 33:1-17.

Andrade, P., V. Castro y C. Aldunate 2016. Reconstrucción del modo de vida de individuos del arcaico de la costa arreica del norte de Chile: una aproximación bioarqueológica desde el sitio Copaca 1. Chungara Revista de Antropología Chilena 48:73-90.

Andrefsky, W. 1994. The geological occurrence of lithic material and stone tool production Strategies. Geoarchaeology 9:375-391.

Andrefsky, W. 1998. Lithics: Macroscopic Approaches to Analysis. Cambridge University Press, Cambridge.

Arnold, J. 1992. Complex Hunter-Gatherer-Fishers of Prehistoric California: Chiefs, specialists, and maritime adaptations of the Channel Islands. American Antiquity 57:60-84.

Arnold, J. 1993. Labor and the rise of complex Hunter-Gatherers. Journal of Anthropological Archaeology 12:75-119.

Arnold, J. 1996. The archaeology of complex Hunter-Gatherers. Journal of Archaeological Method and Theory 3:77-126.

Arnold, J. 2001. The origins of a Pacific Coast Chiefdom. The Chumash of the Channel Islands. The University of Utah Press, Salt Lake City.

Arnold, J. 2004. Foundation of Chumash Complexity. Cotsen Institute of Archaeology, University of California, Los Angeles.

Arnold, J., S. Sunell, B. Nigra, K. Bishop, T. Jones y J. Bongers 2016. Entrenched disbelief: complex Hunter-Gatherers and the case for inclusive cultural evolutionary thinking. Journal of Archaeological Method and Theory 23:448-499.

Aschero, C. 1983. Ensayo para una clasificación morfológica de artefactos líticos. Apéndices A y B. Cátedra de Ergología y Tecnología. Facultad de Filosofía y Letras, Universidad de Buenos Aires.

Aschero, C. y S. Hocsman 2004. Revisando cuestiones tipológicas en torno a la clasificación de artefactos bifaciales. En Temas de Arqueología, Análisis Lítico, editado por M. Ramos, A. Acosta y D. Loponte, pp. 7-25. Universidad Nacional de Luján, Luján.

Ballester, B. y A. Clarot 2014. La Gente de los Túmulos de Tierra. Marmot Impresores, Santiago.

Ballester, B.,A. Clarot y V. Bustos 2014a. Chacaya 2: Reevaluación de un campamento Arcaico Tardío (6000 al 4000 Cal AP) de la costa de Mejillones, II Región, Chile. Werkén 15:31-48.

Ballester, B., A. Clarot, V. Bustos, A. Llagostera y H. Garcés 2014b. Arqueología de la prehistoria de la Península de Mejillones: el campamento de Los Canastos 3 desde sus cuadernos de campo y materiales de museo. Boletín de la Sociedad Chilena de Arqueología 43/44:5-21.

Ballester, B., E. Calás, C. Pelegrino, E. Vidal y P. Aguilera 2017. La vida en comunidad de los cazadores-pescadores marinos del desierto de Atacama (4000-2000 cal. a.C.). En Monumentos funerarios de la costa del desierto de Atacama. Los cazadoresrecolectores marinos y sus intercambios (500 a.C.-700 d.C.), editado por F. Gallardo, B. Ballester y N. Fuenzalida, pp. 183197. CIIR y SCHA, Santiago.

Ballester, B. y M. Crisóstomo 2017. Percutores líticos de la pampa del desierto de Atacama (norte de Chile): Tecnología, huellas de uso, decoración y talladores. Chungara Revista de Antropología Chilena 49:175-192.

Ballester, B. y F. Gallardo 2011. Prehistoric and historic networks on the Atacama Desert coast (northern Chile). Antiquity 85:875889.

Barret, J. 1990. The monumentality of death: The character of Early Bronze Age mortuary mounds in Southern Britain. World Archaeology 22:179-189.

Bate, L. 1971. Material lítico: metodología de clasificación. Noticiario Mensual Museo Nacional de Historia Natural 16 (181/182):3-24. 
Bender, B. 1978. Gatherer-hunter to farmer: A social perspective. World Archaeology 10:204-222.

Berdichewsky, B. 1965. Exploración arqueológica en la costa de la provincia de Antofagasta. Antropología 2:3-30.

Bird, J. 1943. Excavations in northern Chile. Anthropological Papers of the American Museum of Natural History 38:173-318.

Bird, J. 1965. The concept of a "Pre-Projectile Point" Cultural Stage in Chile and Peru. American Antiquity 31:262-270.

Bittmann, B. 1984. El Proyecto Cobija: investigaciones antropológicas en la costa del Desierto de Atacama. $44^{\circ}$ Congreso Internacional de Americanistas, simposio Culturas Atacameñas, pp. 99-146. Manchester.

Bittmann, B. 1986. Recursos naturales renovables de la costa del norte de Chile: Modos de obtención y uso. En Etnografía e Historia del Mundo Andino: Continuidad y Cambio, editado por S. Masuda, pp. 269-334. Universidad de Tokio, Tokio.

Bittmann, B., M. Ahumada y N. Montenegro 1980. El surgimiento, desarrollo, decadencia y abandono de CobijaLamar: notas históricas. En Cobija: proyecto de investigaciones interdisciplinarias en la costa centro sur andina (Chile), editado por B. Bittmann, pp. 63-120. Universidad de Norte, Antofagasta.

Blanco, J. 2013. La Extracción Prehispánica de Recursos Minerales en el Internodo Quillagua-Costa, Desierto De Atacama. Memoria de Arqueólogo, Universidad de Chile, Santiago.

Blanco, J., I. Correa, C. Flores y G. Pimentel 2017. La extracción prehispánica de recursos minerales en el internodo QuillaguaCosta, Desierto de Atacama. Estudios Atacameños 56:77-102.

Blanco, J., M. de la Maza y Ch. Rees 2010. Cazadores recolectores costeros y el aprovisionamiento de recursos líticos. Perspectivas interpretativas de los eventos de talla en el desierto absoluto. Werkén 13:45-68.

Borie, C., X. Power, S. Parra, H. Salinas, P. Rostan, P. Galarce, I. Peña y F. Traverso 2017. Tras la huella del sílice pampino: nuevas metodologías para el rastreo de las áreas fuente de aprovisionamiento lítico en Taltal. Estudios Atacameños 56:103-131.

Brantingham, P., J. Olsen, J. Rech y A. Krivoshapkin 2000. Raw Material Quality and Prepared Core Technologies in Northeast Asia. Journal of Archaeological Science 27:255-271.

Brown, J. 1995. On mortuary analysis with special reference to the Saxe-Binford Research Program. En Regional Approaches to Mortuary Analysis, editado por L. Anderson, pp. 3-26. Plenum Press, New York.

Capdeville, A. 1928. Como descubrí la industria paleolítica americana de los Sílices negros tallados, en la zona de la costa de Taltal. Revista Chilena de Historia Natural 32:348-364.

Castro, V., C. Aldunate, V. Varela, L. Olguín, P. Andrade, F. García-Albarido, F. Rubio, P. Castro, A. Maldonado y J. Ruz 2016. Ocupaciones Arcaicas y probables evidencias de navegación temprana en la costa arreica de Antofagasta, Chile. Chungara Revista de Antropología Chilena 48:503-530.

Claassen, C. 2000. Quantifying Shell: Comments on Mason, Peterson, and Tiffany. American Antiquity 65:415-418.

Contreras, R. J. Cruz, H. Garcés, A. Llagostera, P. Núñez, O. Rodríguez, G. Becerra y H. Gárate 2008. Los Bronces-1: un asentamiento de 5.500 años en la costa de Taltal. Taltalia 1:61-74.

Contreras, R., P. Núñez, A. Llagostera, J. Cruz, A. San Francisco, B. Ballester, O. Rodríguez y G. Becerra 2011. Un conglomerado del período Arcaico costero Medio del área Taltal Paposo, Norte de Chile. Taltalia 4:7-31.

Craig, A. 1982. Ambiente costero del norte de Chile. Chungara Revista de Antropología Chilena 9:4-20.

Day, J., J. Gunn, W. Folan, A. Yáñez-Arancibia y B. Horton 2012. The Influence of Enhanced Post-Glacial Coastal Margin Productivity on the Emergence of Complex Societies. The Journal of Island and Coastal Archaeology 7:23-52.

Fazekas, I. y F. Kósa 1978. Forensic Fetal Osteology. Akadémiai Kiadó, Budapest.

Feinman, G. y J. Nietzel 1984. Too many types: An overview of sedentary prestate societies in the Americas. Advances in Archaeological Method and Theory 7:39-102.

Firth, R. 1946. Malay fishermen: their Peasant Economy. Kegan Paul, Trench, Trubner \& Co. Ltd., Londres.

García-Albarido, F. 2012. Estrategias de Subsistencia en Cobija durante el Periodo Intermedio Tardio y el Tawantinsuyu. Aproximación desde la Funcionalidad de los Instrumentos Líticos. Memoria para optar el título de Arqueólogo, Universidad de Chile, Santiago.

Glassow, M. 2000. Weighing vs. counting shellfish remains: A comment on Mason, Peterson, and Tiffany. American Antiquity 65:407-414.

González, B., R. Palma, B. Zapata y J. Marín 2006. Taxonomic and biogeographical status of guanaco Lama guanicoe (Artiodactyla, Camelidae). Mammal Review 36:157-178.

Haas, J., W. Creamer y Á. Ruiz 2008. Power and the Emergence of Complex Polities in the Peruvian Preceramic. Archaeological Papers of the American Anthropological Association 14:37-52.

Harris, O. 2014. (Re)assembling communities. Journal of Archaeological Method and Theory 21:76-97.

Herrera, C. y E. Custodio 2014. Origin of waters from small springs located at the northern coast of Chile, in the vicinity of Antofagasta. Andean Geology 41:314-341.

Hogg, A., Q. Hua, P. Blackwell, M. Niu, C. Buck et al. 2013. SHCal13 Southern Hemisphere Calibration, 0-50,000 years cal BP. Radiocarbon 55:1889-1903.

Huntington, R. y P. Metcalf 1979. Celebration of Death. The Anthropology of Mortuary Ritual. Cambridge University Press, Cambridge.

Ingold, T., D. Riches y J. Woodburn 1988. Hunter and Gatherers. BERG, Washington DC.

Kaufmann, C. 2008. Metodologías para la Construcción de Perfiles de Mortalidad y Determinación de la Estacionalidad en Restos Óseos de Guanacos (Lama guanicoe): su Aplicación a Sitios Arqueológicos de la Región Pampeana. Colección Tesis Doctorales, Sociedad Argentina de Antropología, Buenos Aires.

Kennett, D., B. Winterhalder, J. Bratruff y J. Earlandson 2009. An Ecological Model for the Emergence of Institutionalized Social Hierarchies on California's Northern Channel Islands. En Pattern and Process in Cultural Evolution, editado por S. Shennan, pp. 297-314. University of California Press, Berkeley.

Latcham, R. 1939. La edad de piedra en Taltal. Boletín del Museo Nacional de Historia Natural 17:3-32.

Le Paige, G. 1970. Industrias Líticas de San Pedro de Atacama. Editorial Orbe, Santiago. 
Llagostera, A. 1979. 9700 years of maritime subsistence on the pacific: an analysis by means of bioindicators in the North of Chile. American Antiquity 44:309-324.

Llagostera, A. 1989. Caza y pesca marítima (9.000 a 1.000 a.C.). En Prehistoria desde sus Orígenes hasta los Albores de la Conquista, editado por J. Hidalgo, V. Schiappacasse, H. Niemeyer, C. Aldunate e I. Solimano, pp. 57-79. Editorial Andrés Bello, Santiago.

Llagostera, A. 2013. Poblaciones marítimas con arquitectura. Hombre y Desierto 17:151-183.

Llagostera, A., R. Weisner, G. Castillo, M. Cervellino y M. Costa-Junqueira 2000. El Complejo Huentelauquén bajo una perspectiva macroespacial y multidisciplinaria. Actas del XIV Congreso Nacional de Arqueología Chilena, pp. 461-480. Museo Regional de Atacama, Copiapó.

Marquet, P., C. Santoro, C. Latorre, V. Standen, S. Abades, M. Rivadeneira, B. Arriaza y M. Hochberg 2012. Emergence of social complexity among coastal hunter-gatherers in the Atacama Desert of northern Chile. PNAS 109:14754-14760.

Morris, I. 1991. The Archaeology of Ancestors: The Saxe/ Goldstein hypothesis revisited. Cambridge Archaeological Journal 1:147-169.

Moseley, M. 1975. The Maritime Foundations of Andean Civilization. Cummings, Menlo Park.

Mostny, G. 1964. Arqueología de Taltal: epistolario de Augusto Capdeville con Max Uhle y otros. DIBAM, Santiago.

Muñoz, I. 2013. Paisaje monumental y complejidad social en los pescadores arcaicos de la costa de Arica: análisis de materialidad y arte pictórico en la cueva La Capilla. Boletín del Museo Chileno de Arte Precolombino 18 (1):25-48.

Núñez, L. 1968. Subárea Loa-Costa Chilena desde Copiapó a Pisagua. Actas del XXXVII Congreso Internacional de Americanistas, pp. 145-182. Librart, Argentina.

Núñez, L. 1984. Secuencia de asentamientos prehistóricos del área de Taltal. Futuro 8:28-76.

Núñez, L. 1999. Archaic adaptation on the South-Central Andean Coast. En Pacific Latin America in Prehistory. The Evolution of Archaic and Formative Cultures, editado por M. Blake, pp. 199211. Washington State University Press, Washington DC.

Núñez, L. y C. Santoro 2011. El tránsito Arcaico-Formativo en la circumpuna y valles occidentales del Centro Sur Andino: hacia los cambios "neolíticos". Chungara Revista de Antropología Chilena 43 Número Especial Tomo1 pp. 487-530.

Núñez, L. y J. Varela 1967/1968. Sobre los recursos de agua y el poblamiento prehispánico de la costa del Norte Grande de Chile. Estudios Arqueológicos 3/4:7-41.

Núñez, L., V. Zlatar y P. Núñez 1974. Caleta Huelén 42: una aldea temprana en el norte de Chile (nota preliminar). Hombre y Cultura 2:67-103.

Núñez, P. 2016. Vivir después de Soñar. Colección Bergantín Águila, Museo Augusto Capdeville Rojas de Taltal, Taltal.

Núñez, P. y R. Contreras 2011. Arte abstracto y religiosidad en el arcaico costero: Punta Negra 1-c, Paposo, Taltal, Norte de Chile. Taltalia 4:33-62.

Oltremari, J., F. Schelegel y R. Schalatter 1987. Perspectiva de Morro Moreno como área silvestre protegida. Bosque 8(1):21-30.

Oyarzún, A. 1916. La estación paleolítica de Taltal. Revista Chilena de Historia y Geografía 19 (23):48-59.
Peralta, P., C. González, C. Westfall y G. Santander 2010. Primeras aproximaciones sobre la arqueología de Pampa Austral: explotación y tecnología lítica al interior de la región de Atacama (Chile). Actas del XVII Congreso Nacional de Arqueología Chilena Tomo I, pp. 297-306. Ediciones Kultrún, Valdivia.

Pimentel, G., Ch. Rees, P. de Souza y L. Arancibia 2011. Viajeros costeros y caravaneros. Dos estrategias de movilidad en el Período Formativo del Desierto de Atacama, Chile. En En Ruta. Arqueología, Historia y Etnografía del Tráfico Sur Andino, editado por L. Núñez y A. Nielsen, pp. 43-81. Encuentro Grupo Editor, Córdoba.

Pozorski, T. y S. Pozorski 1993. Early complex society and ceremonialism on the Peruvian North Coast. Senri Ethnological Studies 37:45-68.

Roddick, A. 2013. Temporalities of the Formative Period Taraco Peninsula, Bolivia. Journal of Social Archaeology 13:287-309.

Roddick, A. y A. Stahl 2016. Knowledge in Motion: Constellations of Learning across Time and Place. The University of Arizona Press, Tucson.

Rostworowski, M. 2004. Costa Peruana Prehispánica. IEP Ediciones, Lima.

Salazar, D., V. Figueroa, P. Andrade, H. Salinas, X. Power, S. Rebolledo, S. Parra, H. Orellana y J. Urrea 2015. Cronología y organización económica de las poblaciones arcaicas de la costa de Taltal. Estudios Atacameños 50:7-46.

Santoro, C., B. Arriaza, V. Standen y P. Marquet 2005. People of the Coastal Atacama desert living between sand dunes and waves of the Pacific Ocean. En Desert Peoples, Archaeological Perspectives, editado por P. Veth, M. Smith y P. Hiscock, pp. 243-260. Blackwell, Oxford.

Sassaman, K. 2007. Complex Hunter-Gatherers in evolution and history: A North American perspective. Journal of Archaeological Research 12:227-280.

Schaefer, M., S. Black y L. Scheuer 2009. Juvenile Osteology: A Laboratory and Field Manual. Elsevier Academic Press, San Diego.

Scheuer L. y S. Black 2000. Developmental juvenile osteology. Elsevier Academic Press, San Diego.

Schoembucher, E. 1988. Equality and hierarchy in maritime adaptation: The importance of flexibility in the social organization of a South Indian fishing caste. Ethnology 27:213-230.

Shady, R., C. Dolorier, F. Montesinos y L. Casas 2000. Los orígenes de la civilización en el Perú: el área norcentral y el valle de Supe durante el Arcaico Tardío. Arqueología y Sociedad 13:13-48.

Smith, H. 1984. Patterns of molar wear in hunger-gatherers and agriculturalists. American Journal of Physical Anthropology 63:39-56.

Standen, V., C. Santoro y B. Arriaza 2004. Síntesis y propuestas para el período Arcaico en la costa del extremo norte de Chile. Actas XV Congreso de Arqueología Chilena. Chungara Revista de Antropología Chilena Tomo 1:201-212.

Stuiver, M., P. Reimer y R. Reimer 2005. CALIB 5.0. http:// intcal.qub.ac.uk/calib/manual/index (30 abril 2017).

Suttles, W. 1960. Affinal ties, subsistence, and prestige among the Coast Salish. American Anthropologist 62:296-305.

Testart, A. 1981. Pour une typologie des chasseurs-cueilleurs. Anthropologie et Sociétés 5:177-221.

Testart, A. 1982. The significance of food storage among huntergatherers: Residence patterns, population densities, and social inequalities. Current Anthropology 23 (5):523-537. 
Testart, A. 1988. Appropriation of the social product and production relations in hunter-gatherer societies. Dialectical Anthropology $12: 147-164$.

True, D. 1975. Early maritime cultural orientations in prehistoric Chile. En Maritime Adaptations of the Pacific, editado por R. Casteel y G. Quimby, pp. 89-143. Mounton Publishers, París.

Uhle, M. 1916. Sobre la estación Paleolítica de Taltal. Revista Chilena de Historia y Geografía 20 (24):47-66.

Uhle, M. 1917. Sobre la estación Paleolítica de Taltal. Publicaciones del Museo de Etnología y Antropología 1:31-50.
Urrejola, C. y M. Orellana 2000. Explotación de Recursos Líticos de la zona desértica al interior de Taltal. Resúmenes del $X V$ Congreso Nacional de Arqueología Chilena, pp. 86-87. Universidad de Tarapacá, Arica.

Yesner, D. 1980. Maritime hunter-gatherers: Ecology and prehistory. Current Anthropology 21:727-750.

Zlatar, V. 1983. Replanteamiento sobre el problema Caleta Huelén 42. Chungara Revista de Antropología Chilena 10:21-28.

Zlatar, V. 1989. Un yacimiento precerámico y su problemática desde la perspectiva de sus recintos habitacionales. Hombre y Desierto 1:1-36. 